\title{
Computational histopathology and deep transfer learning: characterizing the molecular basis of tumor morphology
}

\section{William R. Macon ${ }^{1}$}

Published online: 5 November 2020

(C) Springer-Verlag GmbH Germany, part of Springer Nature 2020

In a 1989 paper titled "Cancer as a disease of DNA organization and dynamic cell structure" [1], the late Donald S. Coffey, an eminent cancer researcher at Johns Hopkins School of Medicine for a half century, and colleagues noted that genetic instability is the driving force for tumor cell heterogeneity in malignancies, "however, it is unknown whether cell structure determines this instability or whether the instability of the DNA itself produces the instability of structure." Regardless, they recognized that to further understand the cancer process required defining the relationship between genetic instability and the alteration of cell structure [1].

Currently, cancer diagnostics and prognostics is largely a multi-step process. The diagnostic aspect is based on changes in cell structure and histopathologic patterns compared to normal as observed through the light microscope. Clinically relevant morphologic features also help determine prognosis, which is now augmented by identifying specific cytogenetic and molecular genetic abnormalities in the laboratory that reflect the genetic instability of cancer cells.

But, what if there were a single technology that would help improve on diagnostics while also predicting that a certain genetic abnormality was present in a malignant tumor? In a recent paper from the European Molecular Biology Laboratory, European Bioinformatics Institute (EMBL-EBI), the authors used computational histopathology analysis with deep transfer learning to accurately classify 28 cancer types and to correlate the morphologic features with the presence of recurrent genetic abnormalities, including whole-genome duplications, copy number alterations, and point mutations, across cancer types [2]. The algorithm developed could also correlate computational histologic features of most of 18 can-

William R. Macon

macon.william@mayo.edu

1 Mayo Clinic, Rochester, MN, USA cer types studied with patient prognosis as defined by overall survival, and its prognostic accuracy was often better than that achieved by traditional tumor classification and grading [2].

None of the cancer types in this study was of hematopoietic or lymphoid origin, but the methodology may be applicable to hematopathology. For instance, TP53 mutations were predicted in a large subset of the cancer types tested [2], which might prove useful if translatable to the evaluation of mantle cell lymphomas [3]. Additionally, $B R A F$ mutations were accurately predicted in thyroid tumors [2], which might have value in the work-up and therapy of histiocytic and dendritic cell proliferations [4].

Although the technology used is not yet ready to be employed in clinical practice (e.g., the study used fresh frozen tissue samples only and tested a small number of total human cancers), it is further evidence of advances in digital pathology and artificial intelligence that may augment pathology workflows in the future without replacing pathologists. The authors' assertion that "histopathology (cellular morphology) is a reflection of the underlying molecular (genetic) alterations rather than an independent trait" [2] is consistent with one-half of Coffey's perspective but still leaves open the possibility that alterations in cellular structure determine genetic instability.

\section{References}

1. Pienta KJ, Partin AW, Coffey DS (1989) Cancer as a disease of DNA organization and dynamic cell structure. Cancer Res 49:2525-2532

2. Fu Y, Jung AW, Torne RV, Gonzalez S, Vöhringer H, Shmatko A, Yates LR, Jimenez-Linan M, Moore L, Gerstung M (2020) Pancancer computational histopathology reveals mutations, tumor composition and prognosis. Nat Cancer 1:800-810. https://doi.org/10. 1038/s43018-020-0085-8

3. Halldórsdóttir AM, Lundin A, Murray F, Mansouri L, Knuutila S, Sundström C, Laurell A, Ehrencrona H, Sander B, Rosenquist R 
(2011) Impact of TP53 mutation and 17p deletion in mantle cell lymphoma. Leukemia 25:1904-1908

4. Hervier B, Haroche J, Arnaud L, Charlotte F, Donadieu J, Néel A, Lifermann F, Villabona C, Graffin B, Hermine O, Rigolet A, Roubille C, Hachulla E, Carmoi T, Bézier M, Meignin V, Conrad M, Marie L, Kostrzewa E, Michot J-M, Barete S, Taly V, Cury K, Emile J-F, Amoura Z, French Histiocytoses Study Group (2014)
Association of both Langerhans cell histiocytosis and ErdheimChester disease linked to the $B R A F^{\mathrm{V} 600 \mathrm{E}}$ mutation. Blood 124: $1119-1126$

Publisher's note Springer Nature remains neutral with regard to jurisdictional claims in published maps and institutional affiliations. 